\title{
elyra
}

\section{A matéria poética de Ana Hatherly}

\section{Lígia Bernardino \\ Universidade do Porto}

Resumo: Técnica disruptora de classificações estanques, a colagem permite o diálogo interartes tanto quanto incita uma leitura plural e predisposta ao novo. Estes pressupostos invadem a obra de Ana Hatherly, principalmente na sua fase experimentalista, que decorre entre os anos de 1960 e inícios dos anos de 1980. Percorrer a pintura e os livros criados pela autora no período de tempo indicado implica perceber-lhe a vocação para a intermedialidade, que também a colagem explicita, entre a vontade de inovação e a consciência do passado histórico e artístico.

Palavras-chave: Ana Hatherly, colagem, experimentalismo, escrita, pintura

\begin{abstract}
As a disruptive technique that undermines encapsulated categories, collage enables the dialogue between different forms of art, as much as it favours a plural undogmatic sort of reading. Ana Hatherly's work illustrates this perspective, mainly in her experimentalist phase, which occurred during the 1960s and until the beginning of the 1980s. By perusing her paintings and books from this period of time it is possible to understand her vocation for intermediality, made explicit by collage, which also reveals the conciliation
\end{abstract} between innovation and the awareness of past history and art.

Keywords: Ana Hatherly, collage, experimentalism, writing, painting 


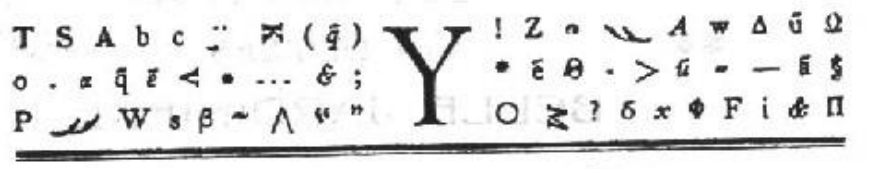

“Manucure”, Mário de Sá-Carneiro (1915: 33)

\section{A colagem enquanto conceito operatório}

A obra de Ana Hatherly encontra na materialidade da linguagem e na visualidade proporcionada pela forma de letras e versos a sua linha condutora. Escrita e pintura, vanguarda e tradição, ideia e objeto constituem-se como binómios estruturantes que, apesar de aparentemente distintos, indiciam a conciliação do díspar nas obras produzidas. A colagem surge como técnica possível para a conceção de literatura e artes plásticas. Nota-se na obra da autora o fascínio pela escrita no que ela tem de mais objetificável: o desenho das letras, os caligramas, a mancha gráfica. O trabalho manual que se indicia no termo «colagem» aproxima-se do posicionamento criativo da autora, já que implica tanto a experimentação, quanto os objetos e instrumentos necessários para que a obra exista. Regista-se, portanto, um processo dinâmico de concreção, a que Hatherly adere num programa consciente de criação poética aberta à interseção de saberes e de formas de expressão diversas.

A poesia de Ana Hatherly enquadra-se no conceito de "arte total» que, como Piero Ceccucci afirma, "requer também da parte do leitor uma autêntica revolução cultural" (2009). Historicamente, essa atmosfera antecede a deposição do regime ditatorial do Estado Novo, a 25 de abril de 1974, e estende-se pelos dez anos que se lhe seguiram, instigando pensamento e criação artística dos autodenominados poetas experimentalistas portugueses. Este grupo, em que se incluem E. M. de Melo e Castro, António Aragão e Alberto Pimenta, 
para além de, inicialmente, Herberto Helder e António Ramos Rosa, empreende um trabalho de síntese. Assumindo uma posição de vanguarda, estes criadores negam um posicionamento de rutura total que os movimentos modernistas de início de século XX preconizavam, optando pela assimilação do antigo e pela sua transfiguração partindo de pressupostos estruturalistas e das emergentes teorias semióticas. Há assim a vontade de delineação de um programa bem definido e que se manifesta tanto nos diversos textos teóricos, quanto nas novas experiências poéticas.

As revistas Poesia Experimental 1 e Poesia Experimental 2, publicadas em 1964 e 1966, inauguram este movimento. No primeiro número desta revista, Herberto Helder usa a alegoria de um pintor que, quando tenta retratar um peixe vermelho, repara que ele se está a tornar preto. O pintor decide, pois, figurá-lo com a cor amarela, convencido de que só a metamorfose unifica o real e o imaginário. Herberto Helder explica que

a tradição é um movimento. Em princípio, não existe nenhum trabalho criativo que não seja experimental, nesse sentido de que ele supõe vigilância sobre o desgaste dos meios que utiliza e que procura constantemente recarregar de capacidade de exercício. A linguagem encontra-se sempre ameaçada pelos perigos de inadequação e invalidez. É algo que, no seu uso, se gasta e refaz, se perde e ajusta, se organiza, desorganiza e reorganiza - se experimenta. (1964: 34)

A experimentação artística acontece através da metamorfose do existente, real ou não. Acontece ainda devido aos instrumentos ao seu dispor - o verbo de ação "utiliza" sugere o manuseio de um objeto, ao passo que o "exercício" implica um estudo prévio ou um treino. Já a dificuldade no uso da linguagem indicia o dinamismo que a comunicação lhe imprime e que a gasta ou renova. Também Herberto Helder estava a par das teorias do signo que estes criadores usaram como fundamento teórico para a conceção das suas obras. Por isso termina o texto constatando que a liberdade é, "tanto em sentido estético como moral, o primeiro dos signos - o da eficácia" (ibidem).

Assim, o novíssimo peixe amarelo converte-se num grande significante para exprimir o fervor libertário da criação. Numa leitura semiótica, a imagem criada pelo pintor furta-se a conotações simbólicas, porque solta de referências culturalmente identificáveis. Conforme refere António Aragão, "os símbolos gastam-se como as baterias: descarregam-se" (1964: 53), e é nessa falência de uma simbolização perene do real que entram em jogo os sinais, 
tornados "evidências que permanecem sempre apontando" (ibidem). As referências semiológicas são evidentes. Dissociar "sinal" de "símbolo" foi uma preocupação dos precursores da semiótica e que Roland Barthes sintetiza explicando que "o sinal e o índice formam um grupo de relata desprovidos de representação psíquica, enquanto no grupo adverso, símbolo e signo, essa representação existe" (Barthes 1985: 34). Ora, convocando o sinal, Aragão percebe a possibilidade de abertura a interpretações múltiplas que os experimentalistas têm como objetivo.

Para este criador, as colagens surgem como resultado do novo posicionamento criativo. No futurismo, elas pretendem criar uma disrupção da linguagem e salientar o frémito do novo homem mecanizado, como se nota em "Manucure", de Mário de SáCarneiro, poema em que carateres tipográficos se intercalam com versos. Os surrealistas buscam nelas sentidos oníricos e/ou inconscientes. Nas décadas de 1960 a 1980, os experimentalistas adotam uma posição diferente. Segundo Aragão, "as colagens e a série de objectos encontrados pretendem em especial potencializar-se, isto é, continuarem apenas como objectos, francamente objectos em relação uns com os outros" (54), como se a obra de arte perdesse a possibilidade de categorização rígida para se abrir a uma pluralidade expressiva em que as fronteiras interartes se diluem.

Inserida neste movimento, Ana Hatherly destaca a "queda de fronteiras entre as artes exigida pelas vanguardas [que] produz diferentes desdobramentos, ou, se quisermos, desmembramentos dentro de cada área específica" (1981: 327). Assim, para estes criadores, a obra de arte autonomiza-se na medida em que se concebe enquanto sobreposição de saberes, formas e até matérias, através de um método de colagem real ou metafórico que obriga a uma descodificação ativa por parte do recetor.

Segundo Marjorie Perloff, "collage always involves the transfer of materials from one context to another" (1998). Isso pode acontecer tanto em termos de formas de arte diferenciadas, quanto no uso de elementos de outras obras dentro da mesma expressão artística. No caso da literatura, esta ensaísta exemplifica a colagem através de The Wasteland, de T. S. Eliot, que termina apropriando-se de versos de Dante a Nerval, de canções infantis à tripla repetição de "Shantih" (saudação final dos Upanishads), sem referência de fonte, usando línguas diversas (1922: 60). No processo de criação dos 
autodenominados experimentalistas portugueses, a consciência do impacto que a tradição (ou simplesmente o passado) exerce é tão forte quanto a vontade de inovar, donde a colagem manifestar-se tanto visualmente, quanto através da apropriação e recriação de obras literárias anteriores. Em Ana Hatherly, a colagem surge como meio para promover a articulação entre escrita e pintura.

\section{As imagens escritas}

Como aceder a O Escritor? Este livro de Ana Hatherly, editado em 1975, foi concebido na totalidade ainda em tempos de ditadura, entre 1967 e 1972, mas a sua forma disruptora só poderia ser publicada em tempos mais libertários. Diz a autora no prefácio que se trata de "uma narrativa em 27 fases [em que] cada imagem é um pictograma, um fotograma congelado na página, cujo significado é posto em movimento pela leitura" (1975: 5). Um livro de imagens, portanto, mas que se reivindica enquanto narrativa e a que o leitor pode aceder como se de poesia se tratasse. Trata-se, sobretudo, de traços que se alinham e sobrepõem num intercâmbio de significação e ininteligibilidade, ou significação perante a ininteligibilidade imediata: o ato criativo estende-se à interpretação.

Numa superação da narrativa, as imagens propostas nada explicam, mas sugerem sentidos múltiplos. Segundo Jean-luc Nancy, só o acesso define a poesia, sendo esta concretizável apenas nesse momento de acesso, sem ponto de chegada:

a palavra "poesia» designa tanto uma espécie de discurso, um género no seio das artes, ou uma qualidade que pode apresentar-se fora dessa espécie ou desse género, como pode estar ausente nas obras dessa espécie ou desse género. (Nancy 1996: 9)

Discurso, no sentido pragmático do termo, implica um sistema de comunicação complexo. Por isso Nancy aponta outra forma de acesso à obra: a qualidade que a determina, tendo em conta os elementos que a constituem. Ana Hatherly salienta o facto de a poesia experimental usar qualquer suporte, fruto de "uma pesquisa contínua que se autojustifica" (2001: 7). Depreendem-se assim as possibilidades extralinguísticas que a poesia pode abarcar. Ainda Jean-Luc Nancy: 
«Poesia» não tem exactamente um sentido, mas antes o sentido de acesso a um sentido a cada momento ausente, e transferido para longe. O sentido de "poesia» é um sentido sempre por fazer. (Nancy 1996: 10)

Um "sentido por fazer", mas tentado no momento de acesso: eis o que o leitor/recetor faz ao aceder a O Escritor, de Ana Hatherly, cujo caligrama-síntese é o de uma colagem. Segundo Piero Ceccucci, a obra desta autora "ao abrir-se para o «visual», não só adquire inéditas posturas comunicativas, mas acaba por explorar e pôr em evidência as relações entre os dois códigos" (2009). Talvez seja então esse o desafio lançado por $O$ Escritor, em que os grafemas ganham forma até se constituírem em frases e textos, mas sempre ilegíveis. Há um alinhamento sugerido pela imitação de uma caligrafia que preenche o rosto de perfil em tudo semelhante à imagem aqui reproduzida.

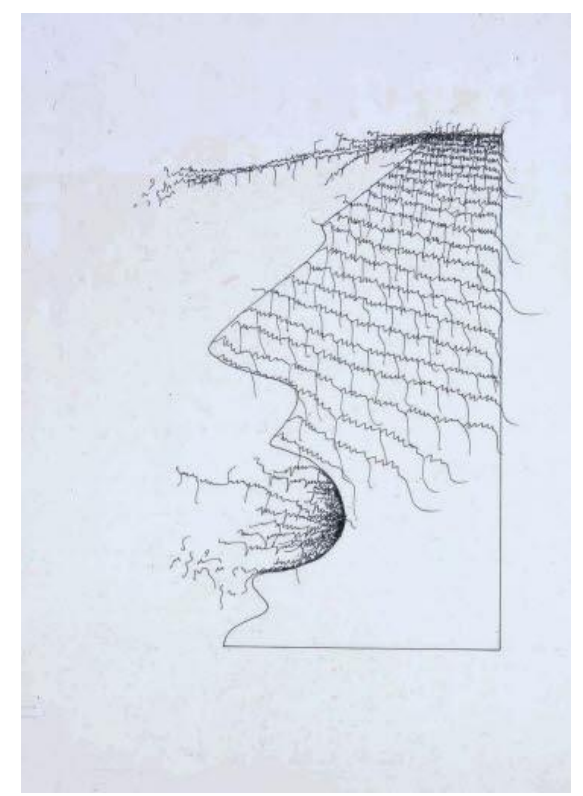

Ana Hatherly, desenho a marcador preto, esferográfica, colagem sobre papel

Em A Casa das Musas e a propósito do texto-visual barroco, a autora refere que não interessa a "intencionalidade da mensagem textual", mas a "intencionalidade poética", detetável na "sobreposição de ikon e logos" (1995: 12). Ora, tal sobreposição é também percetível nesta colagem, pois ainda que o imagético se imponha, são os fatores linguísticos que claramente aqui se invocam. Hatherly desenvolve um especial interesse pela escrita no que ela tem de trabalho manual e de pintura (os ideogramas chineses e os anagramas barrocos têm isso em comum), precisamente devido à visualidade. Paulo Cunha e Silva 
refere a bipolaridade de Ana Hatherly, cuja obra circula entre "escrita ou pintura, pintura ou escrita; escrita e pintura, pintura e escrita" (Silva 1999: 11), isto devido aos estudos que a autora efetuou e à interligação estabelecida na sua obra entre as duas linguagens.

A colagem acima reproduzida explicita o programa da pintora-escritora: "tentar produzir novas formas de praticar a poesia" (Hatherly 2001: 7). Através da visualidade, ela empreende um "exercício e [uma] meditação sobre a linguagem" (ibidem), de que não estão ausentes os estudos então efetuados sobre a teoria do signo de Ferdinand de Saussure: "a língua é um sistema de signos exprimindo ideias" (1981: 83), comenta a autora a partir do linguista suíço. A materialidade do significante (vista por Saussure como a imagem acústica, ou seja, os fonemas) traduz-se aqui em desenho, mas, contrariando a arbitrariedade do signo, a interpretação abre-se ao múltiplo. Tendo por base teórica o estruturalismo, é, no entanto, o pós-estrututalismo que explica o programa criativo de Hatherly. Jacques Derrida defende que "la secondarité qu'on croyait pouvoir réserver à l'écriture affecte tout signifié en général" (1967a: 16), pelo que a escrita se converte em grande significante, ou "signifiant du signifiant" (ibidem), num processo desconstrucionista associável também ao pictograma de Hatherly.

Em O Escritor, as imagens inviabilizam o modo tradicional de descodificação, dada a inexistência de uma escrita reconhecível. No entanto, deteta-se um progresso narrativo partindo da prevalência de carateres que se vão transformando em unidades estruturadas e figuradas pelo pulso de um escritor, até serem consumidas pela boca hiante acima exposta e ordenadas pelo cérebro. O final do livro acentua o abstrato pelas manchas negras (apesar de aparentemente lineares) que indiferenciam os carateres, culminando numa imagem de sequências de letras e números ordenados, o que aproxima a obra às colagens futuristas de inícios de século XX. O convite à interpretação é claro, numa interpelação ao leitor para que acione os seus mecanismos de descodificação. Este radicalismo enquadra-se no que E. M. de Melo e Castro qualifica de "semântica outra" (1977: 12), caraterística que atribui à poesia experimental e que Ana Hatherly desenvolve tanto nas artes plásticas, quanto na escrita.

Marjorie Perloff destaca o caráter duplo da colagem, na medida em que "it refers to an external reality even as its compositional thrust is to undercut the very referentiality it seems to assert" (1998). Portanto, criar tendo como base uma realidade externa. Na obra de 
Ana Hatherly, destacam-se as colagens de cartazes do pós-25 de abril de 1974, resultantes talvez do que Raquel Henriques Silva considera ser "uma paixão cúmplice, envolvida mas distanciada de estímulos exteriores" (2003: 6), tão esclarecedores quanto ao ambiente vivido em Portugal após a revolução do 25 de abril de 1974.

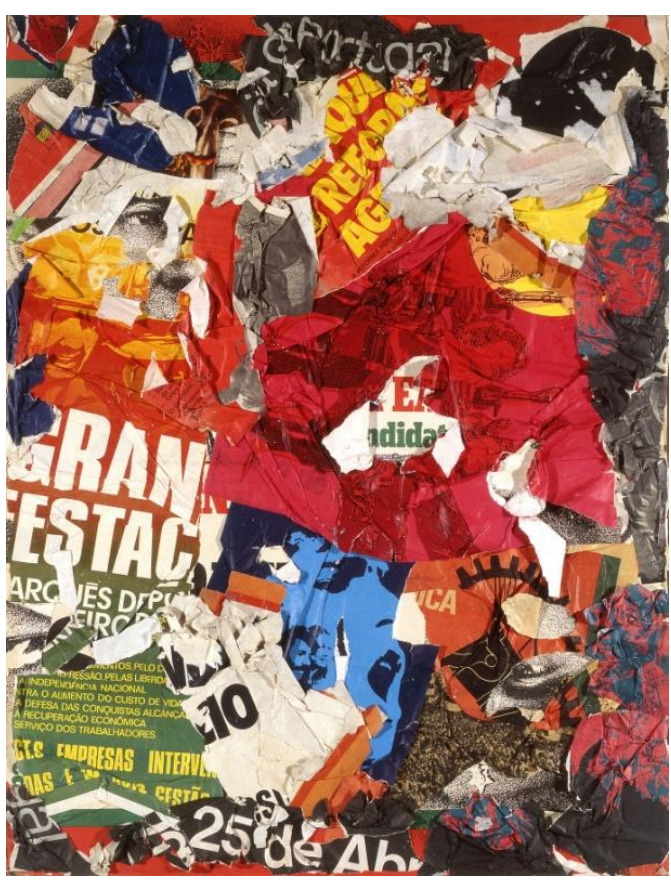

Ana Hatherly, As Ruas de Lisboa, colagem $(110 \times 90 \mathrm{~cm})$, Fundação Calouste Gulbekian (2003a: 105)

Para além dos elementos figurativos de cores profusas condicentes com a atmosfera vivida, destacam-se nesta série denominada de As Ruas de Lisboa (1977), parcialmente publicada em A Mão Inteligente (2003), cartazes com palavras panfletárias recortadas e coladas, reproduzindo mensagens de intervenção e rutura.

Roland Barthes defende que a comunicação acontece no menor ato humano, dado este comportar sempre algum tipo de significação. Tal ideia poderia ser perfilhada por Ana Hatherly, para quem "como em todas as formas de comunicação significativa, tem de se ler o texto sob o texto" (Hatherly 1995: 196). Nesta perspetiva, não há casualidade quando, junto à imagem de Che Guevara, se lê a palavra Cristo escrita a cor-de-rosa em tamanho garrafal (2003a: 103), ou quando, no cartaz reproduzido supra, o papel amarfanhado deixa ler fragmentos de palavras, como "gran" e "estaç", indiciando a expressão "grande manifestação", bem como a data da revolução de 25 de abril (105). A colagem destes cartazes, ou "sobreacumulação de acasos", como João Lima Pinharanda a qualificou (2003: 
13), é significativa. Se a profusão de elementos expõe o continuum histórico, a sua disposição caótica clarifica o espírito de um momento revolucionário, que a obra de arte pretende salvaguardar do esquecimento. Assim se justifica o uso da colagem, forma sugestiva de explicitar as movimentações sociais então vividas.

Para Hatherly, o texto-visual potencia a "capacidade de desenvolver um novo modo de ler os textos, as imagens e tudo o que historicamente se nos oferece como leitura" (1995: 12). A colagem acresce-lhe sentido, ao indiciar as camadas fundadoras do momento criativo e do momento histórico. Não há obra sem contexto ou história, mesmo que esta se recuse, como o fizeram os movimentos modernistas de início do século XX. Marinetti exclama a "revolução tipográfica" (1913: 132). Mário de Sá-Carneiro, em "Manucure", recorta carateres tipográficos tornando-os versos de um poema maior, num elogio à "nova sensibilidade tipografica" (1915: 33). Nestes dois autores, o frémito do novo leva à rejeição ou subalternização do antigo, donde a colagem, forma irreverente de exprimir para além das palavras. O experimentalismo do último quartel do século XX convoca o passado para o ato criativo, ao mesmo tempo que o supera pela contestação e disrupção tanto em termos visuais, quanto na criação literária.

Assim, a colagem sugere o vário que constitui não só a arte, quanto a realidade empírica. Como escreve Hatherly no poema "O voo calmo", inserido na obra Itinerários (2003b), numa fase bem posterior ao experimentalismo,

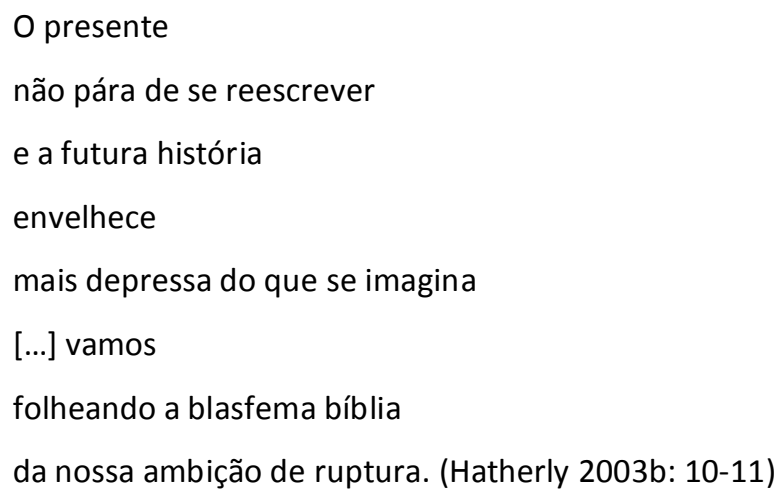

\section{Colagem como tributo}

Pintura da escrita, poesia da imagem: a obra de Ana Hatherly revela o duplo estatuto da autora Ana Hatherly, enquanto pintora e escritora. Como num quiasma barroco, se o 
estudo da escrita enquanto caligrafia tematiza muitas das suas experiências no âmbito das artes plásticas, os poemas até inícios da década de 1980 destacam-se pela potencialização da mancha gráfica. A uni-los está a vontade de trilhar novos rumos artísticos, na consciência de que "desde sempre, se para uns a tradição existe e deve ser imitada, para outros, se existe é para ser reinventada" (Hatherly 1995: 117). A colagem faz parte dessa reinvenção a que Ana Hatherly procede nos poemas integrantes de Leonorana (1970) ou "Anaviva e plurilida", a parte que escreveu para a Joyciana (1982).

Joyciana (1982) exemplifica claramente uma abordagem plural e problematizadora da criação literária em que a colagem ganha evidência. São quatro os autores: Ana Hatherly, E. M. de Melo e Castro, António Aragão e Alberto Pimenta. Cada qual cria um texto que celebra o escritor irlandês James Joyce (donde o título da obra), por alturas do centenário do seu nascimento. No caso de Ana Hatherly, a colagem acontece pela apropriação do início de Finnegans Wake, "glosado e reinventado sistematicamente, como se fosse a raiz profunda duma leitura em superfície" (Hatherly 2001: 338). Já António Aragão procede a uma espacialização de texto e imagem, compostos caricaturalmente, com corruptelas de contornos pornográficos.

A colagem funciona como meio eficaz de concretizar o que António Aragão denomina de "poema objecto", ou seja, uma "proposta de intervenção" capaz de transcender "o simbólico instituído" (1964: 52). Por outro lado, e ainda numa interpretação semiótica, Ana Haherly defende que "toda a arte é metalinguagem" (1967: 137), sendo essa uma porta de acesso possível à interpretação de "Anaviva e plurilida", a parte de que é responsável em Joyciana. Começa com uma citação de Finnegans Wake, livro de James Joyce editado em 1939, convertida numa espécie de epígrafe. Nota-se desde logo uma subversão: a transcrição das últimas linhas da obra de Joyce completa-se com as três linhas do seu início. Num exercício metalinguístico, a autora expõe a circularidade de Finnegans Wake, ao mesmo tempo que lhe presta tributo através de uma colagem feita mote para os poemas que se seguem. A epígrafe é decomposta em versos, cada um dos quais servindo de título aos 23 poemas da autoria de Hatherly.

Segundo Marjorie Perloff, no processo de colagem verbal destacam-se a coordenação e a justaposição, a comparação e o contraste, numa nítida aproximação dos 
termos, dos versos, das frases. Constata ainda que "the things described exist: the poet puts them before us without explicit comment or explanation" (1998). Ora, ao glosar e reinventar esta obra de Joyce, Hatherly procede a uma análise aprofundada, antes de iniciar o processo criativo de conceção de poemas. Curiosamente, o próprio poema 1 destaca as palavras "vigília" e "vigia" (1982: 341), atos conscientes por excelência. Nesta reinvenção de Hatherly, a colagem acontece por intercalamento, não só pela glosa dos versos (sempre no original inglês), como pela inclusão de algumas dessas palavras no poema criado, em tradução ou na língua de partida.

A escolha desta obra de Joyce é significativa. Para o ensaísta Len Plat há em Finnegans Wake uma "potentiality of meaning" (2012: VII), manifestada desde logo nas inúmeras referências culturais que labirinticamente se imiscuem no texto, mas também pelo uso de uma linguagem nova, subversora de regras sintáticas, morfológicas ou semânticas para valorização das tensões exigidas pelo texto, que se autonomiza. As colagens apresentam-se de modo inusitado, frequentemente radical, como através de uma pauta da música, pela inserção de "The Ballad of Persse O’Reilly" (Joyce 1939: 44), através de um diagrama (293) ou mesmo através de notas de margem, como acontece ao longo do capítulo 2 da segunda parte.

Marinetti apregoara já as "palavras em liberdade" (1913: 22), mas esta obra de Joyce procede a uma verdadeira subversão linguística. Tal liberdade criativa coaduna-se com o projeto poético de Hatherly, e é isso que se vê glosado ao longo dos seus poemas de Joyciana. A relação intertextual verifica-se no âmago da linguagem, pelo jogo de fonemas, pela justaposição de sílabas, pela criação de palavras novas, pela disrupção até ao limite da onomatopeia e do silêncio, percetível, por exemplo, nos vazios da mancha gráfica, numa notória e assumida influência das constelações de Mallarmé. Assim, o jogo com a onomatopeia "Ssshhhhh" (Hatherly 1982: 351) que domina o poema 11 de Joyciana é uma reação ou sequência lógica face ao jogo semântico e fonético do título, extraído de Joyce, "We pass through the grass behush the bush to. Whish!". As assonâncias com a vogal fechada /u/ e as aliterações de valor onomatopeico através da fricativa $/ \mathrm{f} /$ presente no extrato de Joyce sugerem um secretismo que o poema de Hatherly vinca. 
A colagem neste exercício poético de Hatherly deteta-se desde logo no título "Anaviva e plurilida". Uma das personagens centrais de Finnegans Wake é Anna Livia Plurabelle: o jogo fonético é por demais evidente. A última palavra sugere a pluralidade de leituras tão suscitada quanto desejada pelos autores experimentalistas. Portanto, a questão autoral deslocaliza-se, assim como a questão da própria obra, já que esta pode ser algo de diferente a cada momento em que é lida: a obra pode ser "plurilida".

Nota-se ainda neste título a semelhança com o nome próprio da autora, o que não é um facto novo: Hatherly elabora muitos jogos fonéticos a partir do seu nome, como se percebe nos títulos Anagramática, Tisanas, Leonorana, Rilkeana e mesmo Joyciana (apesar de, como já referido, esta obra ser um coletivo), e também no interior dos próprios em poemas, como por exemplo em "17. The keys to. Given!":

\author{
anavive \\ anaebela \\ vivaeana \\ viveaana (Hatherly 1982: 357)
}

Tal indiciará também a empatia sentida com ALP, ou Anna Livia Plurabelle, a principal personagem feminina de Finnegans Wake. Ainda segundo Perloff, "the mode of detachment and readherence, of graft and citation, which is collage, is a way of undermining the authority of the individual self" (1998). Como esta ensaísta refere, a colagem comprova a ausência do significado transcendental e este, segundo Derrida, "étend à l'infini le champ et le jeu de la signification" (1967b: 411). O termo "plurilida" encontra assim plena justificação. "Anaviva e plurilida" termina com o poema "23. back to Howth Castle and Environs". Nele, anglicismos colam-se a palavras portuguesas, assonâncias e aliterações vão motivando o seguimento dos versos, a anáfora estabelece analogias cujo sentido se prende apenas ao significante. Assim, a sequência "Howth / house / fauce / face"dá origem a "volta a face", enquanto a sequência anafórica iniciada com "como é belo" desemboca em "como ensina / como ensina" (1982: 364). Para Hatherly, mobilizar as potencialidades da linguagem, pô-la em contacto com textos diversos, combiná-la numa mancha gráfica fazem parte do jogo do 
conhecimento que a arte da escrita proporciona. A irreverência transforma o signo, liberto da arbitrariedade que Saussure lhe atribuiu.

Essa ideia está também patente ao longo de Finnegans Wake, obra em que a significação se dilui nos jogos fonéticos, ou a cadeia de sons gera sentidos de interpretação subjetiva:

Ah, furchte fruchte, timid Danaides! Eno milo melomon, frai is frau and swee is too, swee is two when swoo is free, ana mola woe is we! A pair of sycopanties with amygdaleine eyes, one old obster lumpky pumpkin and three meddlars on their slies. And that was how framm Sin fromm Son, acity arose, finfin funfun, a sitting arrows. Now tell me, tell me, tell me then!

What was it?

A. ....!

?. .. (Joyce 1939: 94)

As referências culturais à mitologia grega e à Bíblia (evidente na referência à cidade do pecado), o vocativo com germanismos, indiciando a maldição que veio a cair sobre as divindades, a sugestão de volúpia ("swee is two when swoo is free") expressam-se através de aliterações e assonâncias tão imprevisíveis quanto elaboradas. O texto - não o autor, não o narrador, nem as personagens - convoca as palavras que foneticamente melhor o exprimirão: o "stream of consciousness", caraterístico deste autor, é menos um processo narrativo do que um imperativo da linguagem.

Há ainda a mancha gráfica e os carateres tipográficos, neste extrato também aproveitados enquanto valor significativo. $\mathrm{O}$ «A» e o «O», o alfa e o ómega: princípio e fim juntos num ciclo vicioso coerente com a própria obra, ao terminar no artigo definido "the" cujo sentido se completa no início da obra, como a epígrafe usada por Hatherly em Joyciana evidencia, ao concretizar o fechamento desse ciclo.

No seu processo de envolvimento com a obra de Joyce, na sua leitura dessa obra, a autora encontra também na irreverência da motivação tipográfica o caminho para a criação literária. O próprio uso da pontuação por parte de Joyce no final do extrato acima destacado sugere um silenciamento, como se a significação transcendesse o que as palavras conseguem enunciar. Talvez seja essa ideia que Hatherly destaca ao defender que "a escrita é muda. O escritor habita o silêncio da palavra porque o texto é uma forma de significado 
originalmente veiculado pelo som, som que a escrita oblitera" (1995: 195). Nesse processo de conversão de som em texto, abrem-se novas possibilidades, designadamente através da harmonização de ikon com logos.

Assim, a colagem pela apropriação de citações suscita uma similitude estrutural percetível no uso da linguagem e da mancha gráfica, apesar de as formas de expressão serem diversas, já que Finnegans Wake foi escrito em prosa e Hatherly encontra na poesia o contraponto para o texto de Joyce. O discurso disruptivo desta narrativa sobrepõe as vozes das personagens, intercala palavras convencionais com corruptelas, usa expressões em diversas línguas e estrangeirismos (alguns deles adulterados), recorre a onomatopeias e inventa palavras.

Ora, todos estes processos estão presentes em Hatherly. Tal adaptação do passado, que mantém um espírito vanguardista, articula-se com o que Marjorie Perloff apelida de movimento de retaguarda: "when [...] an avant-garde movement is no longer a novelty, it is the role of the arrière-garde to complete its mission, to insure its success" (2007: 14). Esta ideia, baseada em William Max, adequa-se aos poemas de Joyciana, na medida em que o tributo a Finnegans Wake não supera o modelo, mas acrescenta-o: a colagem preserva a memória, estabelece linhagens, potencia a (re)descoberta de referências passadas.

\section{Colar-se ao ícone}

Leonorana, cujos poemas foram escritos entre 1965 e 1970, tem como texto de base o vilancete "Descalça vai para a fonte", de Luís de Camões. Nesta obra, composta por 31 variações, a experimentação radicaliza-se, sendo notória a motivação iconográfica que se interliga a anagramas e a poemas-constelação, como abaixo se comprova (a partir do livro Um Calculador de Improbabilidades).

Nestes exercícios visuais, a colagem ao vilancete camoniano revela a importância da intermedialidade na conceção de obra de arte para os autores experimentalistas do último quartel do século XX. A visualidade é apenas um dos recursos que, no caso de Ana Hatherly, é intrinsecamente coerente com a sua atividade de pintora e de escritora. 


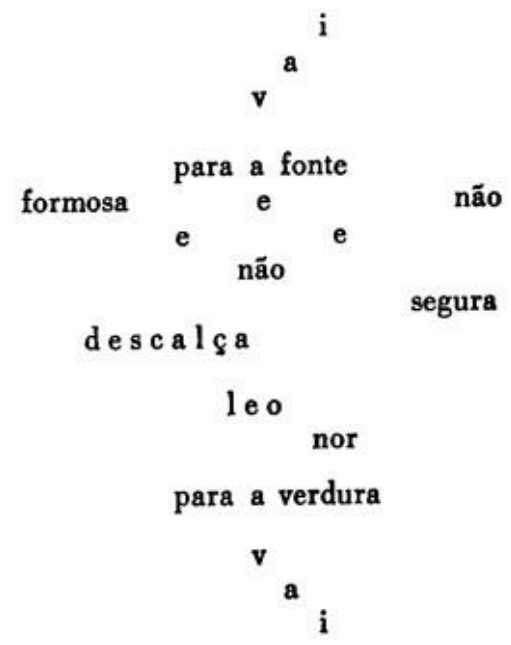

Variação VI (Hatherly 1970a: 202) aaaaaaaaaa L I A N 0 R aaaaaaaaaaaaaaa aaaaaaaaaaaa I A N 0 R L aaaaaaaaaaaaa ąaаaаaаaаaаaа A N O R L I aaaaaaaaaaą aaaaaaaaaaaaaaaa N 0 R L I A aaaaaaaaaa aaaaaaaaaaaaaaaaaa 0 R L I A N aaaaaaaa aaaaaaaaaaaaaaaaaaa R L I A N 0 aaaaaaa aaaaaaaaaaaaaaaaaaaaa L I A N 0 R aaaaa aaaaaaaaaaaaaaaaaa R L I A N 0 aaaaaaa aaaaaaaaaaaaaaaaa 0 R L I A N aaaaaaaa aaaaaaaaaaaaaaaa N 0 R L I A aaaaaaaaaa aaaaaaaaaaaaaa A N O R L I aaaaaaaaaaaa aaaaaaaaaaaa I A N 0 R L aaaaaaaaaaaaaa ananananana $\mathrm{L}$ I A N O R anananananananana

Variação XV (Hatherly 1970a: 211)

Em termos comparativos com escritores da mesma geração, designadamente os de Poesia 61, Rosa Maria Martelo estabelece a diferença entre picture e image:

\begin{abstract}
Ana Hatherly sublinha a dimensão de picture que também pode ser explorada no poema, de resto, sem excluir que esta mantenha articulações com as imagens verbais (daí a pluralidade da leitura defendida), enquanto Gastão Cruz se atém à noção de image, no sentido de imagem mental e de imagem retórica. (2012: 17)
\end{abstract}

A colagem em Leonorana destaca o valor icónico que, metonimicamente, não se cinge à configuração dos poemas na página, mas à própria atualização da figura camoniana que os poemas celebram. Veja-se a "Variação XVIII":

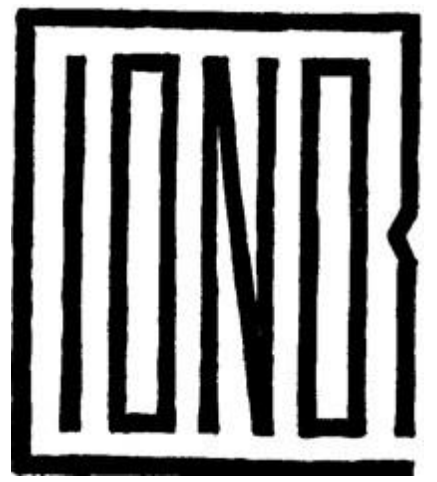

(Hatherly 1970a: 217) 
Também neste poema visual há um círculo que se fecha, constituído pela primeira letra e pela última letra do nome. A sugestão de labirinto que a abertura permite fazer aproxima esta obra dos trompe l'œil barrocos, tão explorados nos anagramas setecentistas. Por outro lado, a grafia não é a usada no século XX, remetendo antes eventualmente para os tempos de Camões. Já a elaborada configuração técnica, pela semelhança a um logótipo, aproxima-o da publicidade, cujo grande impulso acontece a partir dos anos 1950. Este logótipo-colagem corresponde assim a uma síntese de uma época pautada pelo consumo imediato (cuja referência artística mais evidente é a Pop Art) com a tradição dos textos visuais e das grafias que cruzam séculos de escrita.

Através deste tipo de composição poética, a autora confronta o leitor com textos em que a palavra se dilui por entre traços ilegíveis, como a "Variação XIX" (Hatherly 1970a: 219) e a "Variação XX" (221), simulacros apenas de caligrafias. Vê-se ainda confrontado com o radicalismo pelo silêncio, na inserção de uma página em branco, correspondendo à "Variação XVII" (217). A autora explica a intenção destes poemas: "mais do que caligramas esses textos deveriam ser entendidos, isto é, lidos, como ícones pluriformes" (1995: 196). De novo, há um propósito comunicacional mesmo no aparentemente ininteligível que apela a um renovado ato de leitura, dado esta não se restringir a uma descodificação linguística.

Ana Hatherly afirma que, "depois do Futurismo e do Surrealismo, o Experimentalismo veio acentuar a ruptura com os valores tradicionais do tempo no texto valorizando preferencialmente o espaço em que se move a palavra" (2001: 327), numa sugestão de mudança de paradigma em que imagem e palavras não se opõem, mas contribuem conjuntamente para a criação de sentidos e emoções. Para James A. W. Heffernan, a proverbial luta entre imagem e palavra perde justificação, quando se percebe que as similitudes entre as duas formas de criação artística "help us to read - more accurately to construct - the signature of a 'period' or to formulate a master theory of signification" (Heffernan 1993: 1).

Ora, a colagem contribui para o esbatimento da oposição imagem/escrita, que se manifesta na espacialização dos textos. Ao contrário de toda uma tradição que associa às artes plásticas a qualidade de espaço, reservando o tempo para o texto literário, a poesia que mobiliza a mancha gráfica em prol da significação, como acontece em Leonorana, rompe 
com divisões estanques que separem formas de expressão estética. Para os experimentalistas portugueses, tal rutura resultante da sobreposição das artes é mais um modo de intervenção no questionamento do mundo em que vivem.

\section{Materialidades textuais}

Ao incitar a reaprendizagem das palavras a partir da sua materialidade, Ana Hatherly torna o novo tão absolutamente radical que tanto gera a ininteligibilidade, como paradoxalmente impele à busca de significações plurais. Baseado-se em Theodor Adorno, Alberto Pimenta defende que "a poesia não é comunicação mas expressão" (1978: 70). Em suma, despragmatiza-se. A colagem inclui-se neste processo, um entre outros meios de "desvinculação referencial imediata" (122). Sobreposição, convocação de elementos díspares, espacialização promovem, em primeira instância, a perplexidade na interpretação da forma, mas, para Ana Hatherly, essa será uma etapa necessária para que o leitor se inteire da riqueza da poesia. Explica a autora:

Só o principiante ou o autor de pouco alcance exprimirá apenas o que sente: o artífice «ciente» exprime pelo artefacto sobretudo a arte dele; exprime o conhecimento do mundo pela sabedoria das formas; pratica a expressão pela transposição: exprime. (Hatherly 1970b: 376)

Há, portanto, um programa na conceção de arte que os autodesignados experimentalistas portugueses traçaram na prossecução da arte total e que levaram à realização de performances onde a interdisciplinaridade é um fator preponderante. No que diz respeito à poesia, Hatherly concebe os poemas como "verdadeiras construções, obras de "engenharia» onde o «espírito» e a "matéria» se encontram fundidos" (1970b: 376). Deste modo infere a proximidade entre artífice e poeta, fazendo do poema um "objecto-acto [que é] o resultado de um conjunto de regras aplicadas a uma situação específica" (2001: 8).

A poesia concreta será o mais evidente exemplo dessa construção. Foi de Ana Hatherly o primeiro poema concreto a ser publicado em Portugal, em 1959. Como previsão, a autora considerava que as artes ir-se-iam diversificar ao ponto de quebrarem as fronteiras que as separam, sendo os poetas convertidos em "operadores de multi-culturas, abertos a todos os espaços geográficos e temporais" (2001: 388). O poeta converter-se-á em "criador de improbabilidades" (ibidem); os textos "estarão cada vez mais fora das páginas dos livros" 
(ibidem). O conceito de poesia e de poeta transforma-se, em Hatherly, numa fusão de ofícios, em que poiesis se indistingue de tekhnê.

Neste contexto, a colagem assume ainda um valor simbólico: a materialidade do objeto poético é indissociável da manualidade que o poema envolve. Assim, os parónimos materialidade e manualidade aproximam-se para além da semelhança fónica, dada a equiparação sugerida entre objeto poético e artesanato. Em obras como $O$ Escritor ou Leonorana, há uma nítida convocação do labor de poeta que desenhos e grafemas expõem. Para o futuro, Hatherly profetiza a emergência de "criadores polivalentes, operadores de multi-media mas também operadores de multi-culturas" (ibidem), como a poesia digital parece confirmar.

Usando a frase "brings us by a commodius vicus of recirculation", de Finnegans Wake (Joyce 1939: 3), Ana Hatherly brinca com palavras e fonemas, num exercício de justaposição e intercalamento de palavras inglesas e outras reais ou inventadas portuguesas cuja proximidade só existe pela fonética. O poema torna-se assim um jogo linguístico, ao que se une a mobilização da visualidade através da mancha gráfica resultante do intercalamento:

bringus
brincasse
us
asse
by
vai
a
ei
commodius
comódios
vicus
bicos
of
ouve
recirculation
recircoleixam

brincasse 
asse

[...] (Hatherly 1982: 362)

A colagem aqui presente sintetiza o posicionamento poético de Ana Hatherly, que vê na poesia uma materialidade tão sonora (fonemas) quanto visual (grafismo), tão inovadora (distorção das palavras convencionais) quanto agenciadora da memória ("recircoleixam" faz recordar o leixa pren das cantigas medievais). Lúdico e poético entrelaçam-se, potenciando significações extra-linguísticas a captar pluralmente em cada leitura, em cada momento.

No inicío da década de 1970, Hatherly traçou o projeto que "investigar, tanto quanto a minha subjectividade o permitisse, o conhecimento do acto criador e da sua gratuitidade" (Hatherly 1973: 5). Despragmatização da arte como Alberto Pimenta defende, portanto, mesmo se usando matérias prosaicas, mesmo se partindo do mais artesanal artifício. 0 recurso à colagem permite a Ana Hatherly efetuar experimentações que indefinem fronteiras entre a linguagem verbal e o restante universo, entre a literatura e as restantes artes. Torna-se um método propiciador da reconversão, fazendo do novo uma passagem onde múltiplas expressões se anunciam. 


\section{Bibliowebgrafia}

Aragão, António (1981), "Intervenção e movimento", in PO.EX. Textos teóricos e documentos da poesia experimental portuguesa, Lisboa, Moraes Editores, [1964]: 35-36.

Barthes, Roland (2007), Éléments de Sémiologie; ed. ut.: Elementos de Semiologia, tradução de Maria Margarida Barahona, Lisboa, Edições 70 [1985].

Castro, E. M. de Melo e (1981), Texto do catálogo da representação portuguesa de Poesia Experimental (XIV Bienal de São Paulo), in PO.EX. Textos teóricos e documentos da poesia experimental portuguesa, Lisboa, Moraes Editores [1977]: 9-15.

Ceccucci, Piero (2009), "Ikon como Logos. a poesia visual de Ana Hatherly"; in Portuguese Cultural Studies, http://www2.let.uu.nl/solis/psc/p/PVOLUMETWOPAPERS/Ceccucci-P2.pdf. (visto a 13 de fevereiro de 2016).

Derrida, Jacques (1974), De la Grammatologie, Paris, Éditions Minuit [1967a].

-- (1967b), "La structure, le signe et le jeu dans le discours des sciences humaines"; in ed. ut.: L'Écriture et la Différence, Paris, Seuil: 409-428.

Eliot, T. S. (1984), The Waste Land; ed. ut.: A Terra Sem Vida, edição bilingue, tradução Maria Amélia Neto, Lisboa, Ática [1922].

Hatherly, Ana (1981), "Estrutura, código, mensagem", in PO.EX. Textos teóricos e documentos da poesia experimental portuguesa, Lisboa, Moraes Editores [1967]: 135-137.

-- (2001), "Leonorana"; in Um Calculador de Improbabilidades, Lisboa, Quimera [1970a]: 191-233.

-- (2001), "Anagramático - Considerações necessárias", in Um Calculador de Improbabilidades, Lisboa, Quimera [1970b]: 375-378.

-- (1973), Mapas da Imaginação e da Memória, Lisboa, Moraes Editores.

-- (2001), "Notas para uma teoria do poema-ensaio"; in Um Calculador de Improbabilidades, Lisboa, Quimera [1981]: 327-333. 
-- (2001), "Joyciana: Anaviva e Plurilida. 23 variações sobre fragmentos de Finnegans Wake de James Joyce"; in Um Calculador de Improbabilidades, Lisboa, Quimera [1982]: 337-364.

-- (1995), A Casa das Musas, Lisboa, Estampa.

-- (2001), Um Calculador de Improbabilidades, Lisboa, Quimera.

-- (2003a), A Mão Inteligente, Lisboa, Quimera.

-- (2003b), Itinerários, Vila Nova de Famalicão, Quasi.

Heffernan, James A. W. (2004), The Museum of Words. The poetics of ekphrasis from Homer to Ashbery, Chicago, University of Chicago Press [1993].

Helder, Herberto (1981), "Texto-Introdução a Poesia Experimental 1", in PO.EX. Textos teóricos e documentos da poesia experimental portuguesa, Lisboa, Moraes Editores [1964]: 33-34.

Joyce, James (2012), Finnegans Wake, Londres, Wordsworth Editions [1939].

Marinetti, Filippo Tommaso Emilio (1979), "Destruição da sintaxe. Imaginação sem fios. Palavras em liberdade"; in Antologia do Futurismo Italiano - Manifestos e poemas; organização, tradução e notas de José Mendes Ferreira, Lisboa, Vega [1913]: 122-135.

Martelo, Rosa Maria (2012), "De Imagem em Imagem”, in Abril, Revista do Núcleo de Estudos de Literatura Portuguesa e Africana da UFF, Vol. 5, n 9: 15-26.

Nancy, Jean-Luc (2005), Résistance de la Poésie; ed. ut.: Resistência da Poesia, tradução de Bruno Duarte, Lisboa, Vendaval [1997].

Perloff, Marjorie (1998), "Collage and poetry", in Encyclopedia of Aesthetics, ed. Michael Kelly, 4 vols. (New York: Oxford UPress, 1998), Vol 1: 384-87, http://marjorieperloff.com/essays/collage-poetry/ (último acesso a 15 de fevereiro de 2016) -- (2007), "From avant-garde to digital: the legacy of Brazilian concrete poetry"; in Poesia e Outras Artes. Do modernismo à contemporaneidade, Porto, Afrontamento/Instituto de Literatura Comparada Margarida Losa: 11-45.

Pimenta, Alberto (2003), O Silêncio dos Poetas, Lisboa, Cotovia [1978].

-- (1984), Read \& Mad, Lisboa, \& Etc. 
Pinharanda, João Lima (2003), "Imagem-acção"; in Ana Hatherly, A Mão Inteligente, Lisboa, Quimera: 11-17.

Platt, Len (2012), "Introduction"; in James Joyce, Finnegans Wake, Londres, Wodsworth Editions: VI-XXV.

Sá-Carneiro, Mário de (1984), “Manucure”; in Orpheu 2, Lisboa, Ática [1915]: 25-38.

Silva, Paulo Cunha e (2003), Prefácio a: Ana Hatherly, O Pavão Negro, Lisboa, Assírio \& Alvim: 9-13.

Silva, Raquel Henriques (2003), "Ana Hatherly: os campos abertos do (in)dizível"; in Ana Hatherly, A Mão Inteligente, Lisboa, Quimera: 5-11.

Lígia Bernardino concluiu o doutoramento em 2014 na Faculdade de Letras da Universidade do Porto, com a tese intitulada Limiares do Humano, onde desenvolveu um estudo sobre Jorge de Sena, Maria Gabriela Llansol e Gonçalo M. Tavares. Para além da sua atividade de tradução e de docência, tanto no Ensino Secundário, quanto no Ensino Superior, tem vindo a desenvolver projetos de investigação na área da Literatura Portuguesa recente. 